\title{
Job Creation in Italy: Geography, Technology and Infrastructures
}

\author{
Alejandro Cuñat and Giovanni Peri \\ IGIER and CEPR, Università Bocconi IGIER and EUI
}

September 11, 2000

\begin{abstract}
The recent dismal performance of overall job creation has left Italy, as of the end of the 90's, with very low participation and high unemployment rates. Moreover, Italy exhibits a large regional dispersion of those variables when compared to similar European Union economies. The present paper, using Census data on employment from 784 Local Labor Systems (LLS's), covering the whole Italian territory, analyzes job creation and its determinants for the 1981-1996 period. Local characteristics (inputoutput linkages, pool of local workers, technologcal spillovers), technological diffusion and infrastructure provision affect productivity in each LLS and, lacking wage flexibility, they determine differences in job creation across them. We analyze those characteristics across Italian LLS's and regions, developing measures for each of them and then we estimate their impact on job creation. The sizable $(0.8 \%$ a year $)$ difference in employment growth between the Northeast and the Southwest, as well as the overall differences across LLS's are explained up to one third by those characteristics. In particular, strong local input-output linkages across industries and fast growing transport infrastructures are shown to be important determinants of job creation. The southern Italian economy emerges in this analysis as rather differentiated within itself. Some parts of the Southeast show current characteristics compatible with good job creation, particularly if helped by investment in infrastructures. Most of the Southwest, on the other hand, is still lacking local characteristics for self-sustained job creation and has been strongly penalized by the cut in public investment in the 90 's.
\end{abstract}

The authors thank Tito Boeri, Pietro Garibaldi, and Dieter Urban for useful comments on a previous version of the paper, and Andrea Gentilini for excellent research assistance. The usual disclaimers apply.

Address: c/o IGIER via Salasco 3,20138 Milano, Italy.email: ale.cunat@unibocconi.it, giovanni.peri@uni-bocconi.it. 


\section{Introduction}

As economists and policy-makers have often remarked, two disappointing tendencies stand out in the economic performance of Italy in the 80's and early 90's. The first is the dismal performance of job creation during these two decades $^{1}$, granting Italy the last position for employment growth among the large economies of the world. As shown in Table 1, both in the period 19811996 and in the recessional sub-period 1991-1996, Italy has been, by far, the worst performer in terms of employment growth $\left(g_{E}\right)$. Such performance has left Italy in 1998 as the country with the highest unemployment rate $\left(u_{98}\right)$ and the lowest participation rate $\left(p_{98}\right)$ among the large industrialized economies (see Table 1).

Table 1: Employment Performances in G7

\begin{tabular}{lllll}
\hline \hline Country & $g_{E}\left({ }^{\prime} 81-^{\prime} 96\right)$ & $g_{E}\left({ }^{\prime} 91-^{\prime} 96\right)$ & $p_{98}$ & $u_{98}$ \\
\hline USA & 1.74 & 1.08 & 77.7 & 4.5 \\
Japan & 1.02 & 0.63 & 78.1 & 4.1 \\
\hline Germany & 0.37 & -0.28 & 71.2 & 9.4 \\
\hline France & 0.15 & -0.13 & 67.3 & 11.7 \\
\hline Italy & $\mathbf{- 0 . 0 7}$ & $\mathbf{- 0 . 4 5}$ & $\mathbf{5 8}$ & $\mathbf{1 2 . 3}$ \\
\hline UK & 0.72 & .0 .36 & 75.5 & 6.3 \\
\hline Canada & 1.54 & 0.63 & 76.5 & 8.4 \\
\hline Source: OECD Economic Outlook, 1999 \\
\hline \multicolumn{5}{l}{ Employment Growth is in average yearly percentage rates } \\
\hline
\end{tabular}

The second alarming trend is the remarkable regional dispersion in job creation (as well as in GDP growth), which makes Italy the country with the largest regional disparities in unemployment rates among the European Union (hereafter EU) economies as of year 1998. Moreover, lack of employment growth, rather than slow growth in productivity, has been identified as the main contributor to the bad performance of GDP growth in the Mezzogiorno in the 90 's ${ }^{2}$. Figure 1 represents each country of the EU as a vertical segment in the graph, spanning the range of unemployment rates of its regions. The lower bound of the segment (and the value written next to it) corresponds to the lowest regional unemployment rate while the upper bound is the highest regional unemployment rate, while a little horizontal mark indicates the average unemployment rate of the country. As the figure shows, while the Italian northeastern regions perform close to full employment (unemployment rates at 5.1\%) and among the best in Europe, some southern regions agonize at unemployment levels as high as $26 \%$ (Campania).

\footnotetext{
${ }^{1}$ The Italian performance in creating jobs for the years ' 97 , '98 and '99 has been better and close to the average of the seven largest economies.

${ }^{2}$ See Casavola and Sestito [6] and Helg et al. [18] for an account of this fact.
} 


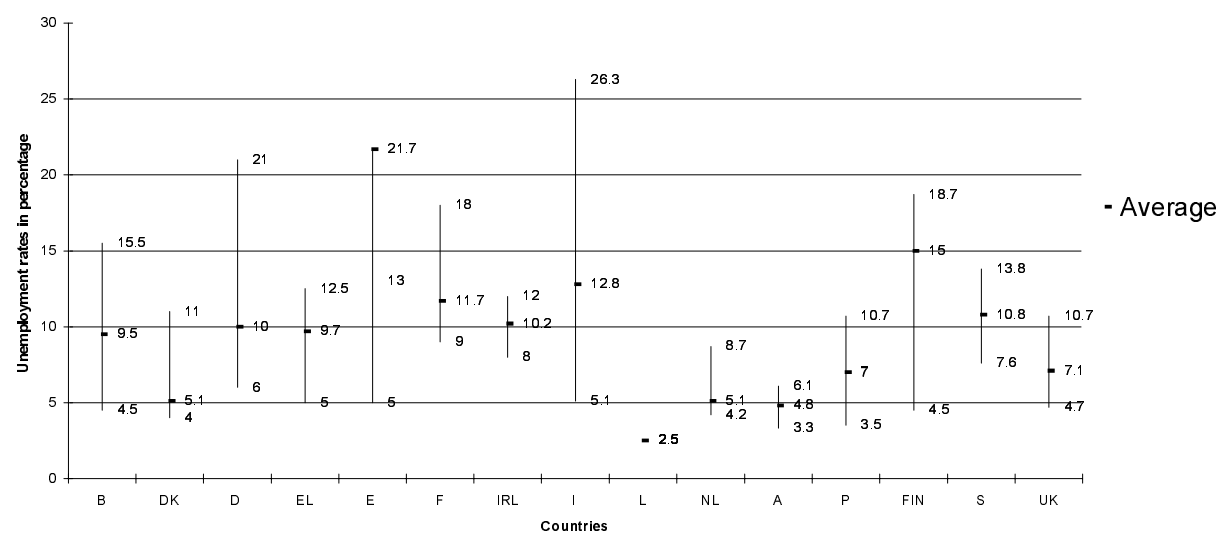

Figure 1: Regional Unemployment Dispersion in EU member States

Analysts and policy-makers have identified some important factors contributing to the disappointing aggregate performance of job creation in the Italian economy. First, the remarkable budgetary adjustment carried out in the 1990-1998 period ${ }^{3}$ has been achieved with tax increases and public investment cuts causing a large negative shock to GDP growth (see European Commission [13] for a detailed analysis). Second, labor market rigidities and difficulties in hiring and firing have often been singled out as structural reasons for such sluggish performances. Reforms in this field are considered as the necessary premises for a more dynamic labor market which efficiently reallocates and creates jobs (see also the last DPEF [11]).

However, these "aggregate" factors leave the large regional disparities in job creation observed in Italy unexplained. Concerns about these large regional differences (and, in particular, about the Mezzogiorno problem) induce policymakers to think hard about new solutions to this long standing problem, promoting a combination of labor market policies, private investment incentives, and public infrastructure provision to revitalize the stagnating economy of some regions. (See the section on Mezzogiorno in DPEF [11] "Premesse e Conclusioni.") Considering the problem of job creation, in order to advance potential explanations and to design the right policies, it is extremely important to have a detailed and reliable representation of employment growth not only across Italian regions, but within regions themselves. Regions in southern Italy are not homogeneous units, and amidst a general disappointing performance some locations and districts have been immensely successful in creating jobs and gen-

\footnotetext{
${ }^{3}$ This adjustment has caused a decrease of nine percentage points of the debt/GDP ratio, allowing Italy to meet the Maastricht criteria and join the EMU in 1998.
} 
erating GDP growth even in the 80's and 90's. Examples are the provinces of Pescara and Teramo in Abruzzo, which have been among the best Italian performers in employment growth and GDP growth, pulled by the success of some booming industrial districts.

Therefore, analyzing small geographical units, should enable us to identify the successful ones in terms of job creation and to look for the local factors which have determined this success; this strategy should also help us assess the importance of regional technological progress and local infrastructures in generating regional employment. This kind of analysis can also be considered as a test of the "industrial districts" theories. Namely we assess the importance of external agglomeration economies, celebrated by the literature on districts ${ }^{4}$, in job creation, and measure how much of the regional disparities in job creation can be traced back to these local factors.

The present paper uses the most reliable and geographically detailed data on employment to construct the map of job creation in the private sector between 1981 and 1996 in Italy at a very fine geographical level (the units of analysis are 784 Local Labor Systems). The data are produced by the Census of Manufactures and Services (ISTAT [21], [22] and [23]). Using these data and regional data from several sources we also assess the importance of local and regional factors in explaining job creation in the 1981-1996 period. We use a rather simple framework for the analysis, assuming that long-run growth of employment in a locality is determined by long-run labor demand. In order to explain different rates of labor creation across Italian local labor systems, we look for local factors that affect productivity growth, and analyze them at the regional and sub-regional level.

Based on the theories of agglomeration externalities, we first analyze structural characteristics that make local systems more productive and thus more likely to generate jobs. Second, we use regional data to calculate rates of technological progress across regions and evaluate its impact on local labor creation. Finally, we consider the effect of public infrastructure in generating employment growth. Our analysis enables us to assess the importance of local and regional structural factors in generating employment. In particular, we are able to tell how much of the regional disparities in job creation is due to local agglomeration economies, technological progress, and creation of infrastructures. These factors are among the most important determinants of productivity and employment growth in the long run. The implications of our analysis are important and far reaching. First of all, we identify the local labor systems which have the strongest potential for future growth, based on their current characteristics (in 1996) and on our estimates. Second, we are able to assess the impact of regional technology and infrastructures on employment creation, so that policies aimed at improving either of them could be evaluated as far as their impact on job creation is concerned.

\footnotetext{
${ }^{4}$ See Beccattini[2] and Brusco[4] among the others
} 
The rest of the paper is organized as follows: Section 2 provides a description of the differences in job creation across macro-areas, provinces and local labor systems in Italy for the 1981-1996 period. Section 3 provides the framework of our analysis, stressing the importance of labor demand and productivity in job creation. Section 4 analyzes the local and regional determinants of productivity and job creation, describing how we measure local agglomeration economies, technological progress and public infrastructures. Section 5 presents the estimates of the effect of these factors on employment growth for the 1981-1996 period. Section 6 performs some projections and assesses the current "job-generating potential" of Italian LLS, which should be helpful to design appropriate policies for the future. Section 7 concludes.

\section{Job Creation: a Descriptive Analysis}

It is important to document the degree of heterogeneity in job creation across the Italian territory, to convince the reader that we can really learn something looking within the country and analyzing such variation. Moreover we will argue that the small geographical units we choose for our econometric analysis, namely the Local Labor Systems (LLS from now on), are the best to carry the analysis of job creation and its local determinants. In this section we present some statistics and some maps to summarize the relevant information on job creation in Italy in the 1981-1996 period, and we provide some information on the data themselves.

As mentioned above we use data from the Italian Census of Manufactures and Services covering the period 1981-1996 (the years of censuses were 1981, 1991 and 1996). The census data contain a count of employees over the national territory, aggregated in 47 sectors (made compatible across censuses) and in 8'100 comuni (very small municipalities comparable to counties in the US). While sticking to the definition of industries provided by ISTAT we have aggregated the data in 784 Local Labor Systems (Sistemi Locali del Lavoro), using the definition provided by Sforzi and technically implemented using the groupings in ISTAT [24]. LLS's are geographical units which, differently from regions and provinces, are not arbitrarily defined from an economic point of view. In fact these units try to match the definition of labor markets as closely as possible in the following sense:

1. They are made of spatially connected counties.

2. More than $75 \%$ of the residents in the unit works in the unit itself.

3. They must be recognized as local labor markets in the sense that local firms mostly employ local work force. 
Thus, these units have been defined keeping in mind that some kind of economic interactions, such as labor pooling and diffusion of technological knowledge, are likely to be more intense within smaller and denser units representing one labor market. The 784 LLS's cover the whole Italian territory, and identify labor markets ranging from large towns (such as Milano, Rome, Torino, Florence), to medium size towns (such as Modena, Padova, Prato, Avellino, Catanzaro), down to very small units.

We consider only the private industrial and service sectors in our analysis. We are aware that a major omission is the public sector (mainly health-care, education and public administration), which is rather large in some regions and has created a large number of jobs. However, we are interested in analyzing the creation of employment in the private sector to isolate the market determinants of differential job creation. The future of job creation in Italy should rely on the private sector anyway as, if anything, public sector's jobs will probably decrease due to privatizations.

\subsection{LLS's, Provinces and Macro-regions}

Discussing labor creation in Italy with an emphasis on its uneven geographical distribution is better done, at first, by choosing different level of geographical aggregation; in this way we perceive the existence of different "levels" of such a problem. First, considering macro-areas (Table 2) we see that the Northeast of the country is consistently the best performing area with positive rates of job creation in the 1981-1996 period (opposite to the rest of the country where jobs have been destroyed or barely kept constant). Even in the recessional phase of the early 90's the Northeast still exhibits an increase in the number of jobs. Remarkably, in this period, it does better than the UK, which has been the country creating jobs at the fastest rate in the last two decades, among the Large European economies. At the opposite end of the range of performance, the Southwest has been consistently the worst performer throughout the period and particularly during the recession 1991-1996. In fact it has destroyed privatesector jobs at a rate of $0.38 \%$ a year. The difference in employment growth between the Northeast and the Southwest has been $0.8 \%$ points a year, which is as large as the difference between the worse (Italy) and the best (UK) European performances in job creation. 
Table 2: Employment Growth in Macro Areas

\begin{tabular}{lll}
\hline \hline Area & $g_{E}\left({ }^{\prime} 81-^{\prime} 96\right)$ & $g_{E}\left({ }^{\prime} 91-^{\prime} 96\right)$ \\
\hline North East & $0.43 \%$ & $0.20 \%$ \\
North West & $-0.33 \%$ & $-0.06 \%$ \\
\hline Center & $0.02 \%$ & $-0.06 \%$ \\
\hline South East & $0.06 \%$ & $-0.46 \%$ \\
\hline South West & $-0.38 \%$ & $-0.53 \%$ \\
\hline Source: Our Calculations on ISTAT data \\
\hline Employment Growth is in average yearly percentage rates \\
\hline
\end{tabular}

This macro-regions' summary conceals some larger differences in the job creation of smaller geographical units, but already gives the feeling of the magnitudes involved. Figure 2 shows geographical differences in detail by disaggregating Italy by province, and representing employment growth in yearly percentage rates with the range of gray color: a darker gray means larger job creation. Besides confirming the concentration of good performing provinces in the Northeast and the concentration of bad performing provinces in the Southwest+islands and the Northwest, Figure 2 also shows the large dispersion of performances. The standard deviation of the distribution of growth rates for provinces is $0.12 \%$, and the difference between the lowest and the highest is around $0.9 \%$.

Finally moving to the smallest geographical units, the LLS's, we observe a remarkable heterogeneity in their size, density and performances. Each of them is considered as one single observation in our econometric analysis. The density of population (in 1996) ranged from 3500 inhabitants per square kilometer in Naples LLS to 10 inhabitants per square kilometer in Crodo LLS (Lombardia). Total population ranged from 3'312'000 in Rome to 2851 in Limone sul Garda (Lombardia). The yearly growth rates of employment (whose summary statistics and top and bottom tails are reported in Table 3 ) in the 1981-1996 period range from $+7.8 \%$ a year in Melfi (Basilicata) to $-6.1 \%$ a year in Pontebba (Veneto). The standard deviation of yearly growth rates of employment is $1.2 \%$ and the top twenty LLS's experienced a growth rate of employment above $2 \%$ a year, which is larger than the best performing countries in the world. Notice that the smaller is the unit of analysis the larger will be the variance across them, simply because we are averaging over a smaller sample. Nevertheless the fact that LLS's are defined as single labor markets, makes them appropriate and meaningful units for the analysis of employment. Therefore looking into the local determinants of such different outcomes is likely to help us learn about the importance of different factors for job creation. 


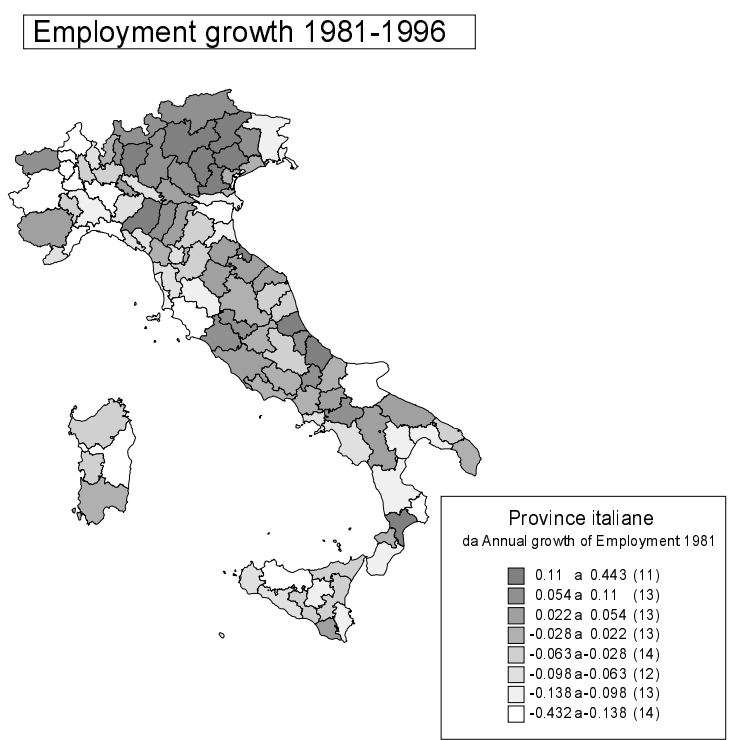

Figure 2: Job Creation in Italian Provinces

Table 3: Employment Growth in LLS

\begin{tabular}{lcll}
\hline \hline Top LLS & $g_{E}\left({ }^{\prime} 81-^{\prime} 96\right)$ & Bottom LLS & $g_{E}\left({ }^{\prime} 81-^{\prime} 96\right)$ \\
\hline Melfi (BAS.) & $7.83 \%$ & Pontebba(VEN) & $-6.0 \%$ \\
Canazei (TAA) & $3.77 \%$ & S. Teresa di Gallura (SAR) & $-4.5 \%$ \\
\hline Pietralcina (CAM) & $3.35 \%$ & Bobbio (FRI) & $-4.08 \%$ \\
\hline Apice (CAM) & $2.70 \%$ & Porto Tolle (VEN) & $-3.71 \%$ \\
\hline Martina Franca (PUG) & $2.60 \%$ & Biccari (PUG) & $-3.59 \%$ \\
\hline Average:-0.4\% & Std. Dev:1.27\% \\
\hline \multicolumn{4}{l}{ Source: Our Calculations on ISTAT data } \\
\hline
\end{tabular}

Before doing that, though, let us also take a look at the sectorial dimension of job creation. Certainly job creation varies largely across sectors. In Europe the service sector, and in particular business, banking and finance services have been the largest creators of jobs while manufacturing has destroyed jobs. In our data the worst performing sector has been "Metallic Products," which lost jobs at a rate of 3\% a year during the 1981-1996 period, while the best performing sector has been "Business services", which created jobs at a rate of $2.8 \%$ per year. We do not intend to analyze the sectorial dimension of the problem in detail; shift-share analysis relative to the Italian economy has been done already (see Garibaldi and Mauro [16] and Marimón and Zilibotti [25]), finding somewhat 


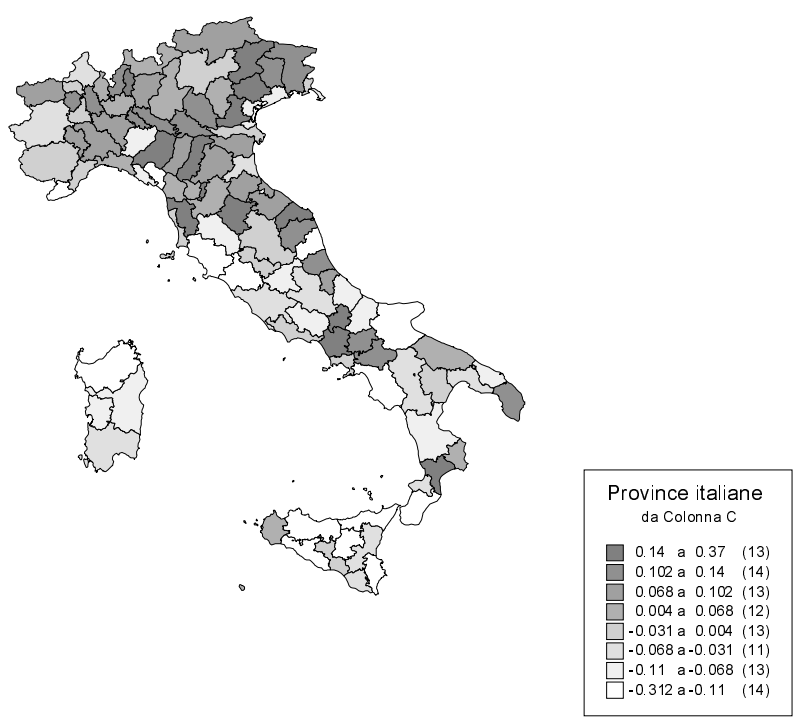

Figure 3: Job Creation net of Industry-Composition

mixed results as far as the sector-contribution to explain job creation in Europe is concerned.

Nevertheless, we claim that our geographical analysis reveals something more than just different job creation rates due to specialization of LLS in different sectors: large differences in job creation persist once we "clean" the sector effect. Figure 3 shows the intensity of job creation in provinces after "cleaning" for its industry composition. Each province's performance is obtained by aggregating the growth rate of employment in all its industries, measured as deviations from their national average . Both from a look at the picture and from summary statistics we notice the excellence of the Northeast, the large dispersion in performances and the disadvantaged position of the Southwest, while the Northwest, once we eliminate the sector effect, does not look as bad as before. The standard deviation of province job creation, after cleaning for the sector effect, is still $12 \%$, the difference top-bottom is $0.78 \%$, and the correlation with the distribution of raw job creation is a very significant 0.53 .

Our focus in the rest of the paper will be, therefore, on explaining these differences, controlling for the sectorial composition of LLS's, but taking into account that inter-sector linkages, local spillovers and local labor pooling could be important reasons why one LLS is more attractive than others for firms to locate and generate new jobs. 


\section{The Labor Demand}

Within a country in which the level of wages grows at a roughly uniform rate across regions, and in which goods are freely traded so as to equalize inflation across regions, labor demand determines employment in each region. Differences in labor demand across locations translate into different rates of employment growth, given the homogeneity on the "supply side" due to wage centralization. What determines demand for labor by firms, in turn, is the productivity of a new job in that location; thus, the factors that make a locality more productive will ultimately support a larger labor demand and employment growth in it.

This idea lies behind many analyses of regional labor markets, and is the basis for our econometric analysis as well. Blanchard and Katz [3], Decressin and Fatás [9], Obstfeld and Peri [27], and several others use exactly this framework when describing the transitional process of regional economies after productivity shocks. Those studies are concerned with the reaction of unemployment rates, participation rates and migration to regional productivity shocks; they show how the long-run effect on employment of such shocks will be adjusted by migratory movements (larger in the US) and changes in participation rates (larger for European Countries). In the present paper we can only assess the long run (15 years) impact of local factors on labor demand and employment growth, due to the frequency of our data. Nevertheless, we share the assumption that longlasting effects on regional employment are the results of different growth rates of labor demand. We illustrate our model by using a graphical representation which justifies the estimating equation. Further details on the derivation of the equation and on the underlying production function can be found in Appendix A1.

\subsection{The Model}

The unit of our econometric analysis is the single industry within a LLS. In particular we assume that real wages are equalized across LLS's ${ }^{5}$. The price of each product is equalized, physical capital is perfectly mobile across LLS and labor is mobile (with sluggishness) across LLS. The production of sector $z$ in location (LLS) $i$ is a function of labor and capital used, of agglomeration externalities, of the technological level and of the level of public capital (infrastructures) in the LLS. More specifically, we assume that returns to scale to labor and capital in a LLS/industry are decreasing (due to local fixed factors); however, when including public capital, the aggregate production function in the LLS exhibits constant returns to scale ${ }^{6}$. We measure technological progress and infrastructure endowments only at the regional level, and therefore assume that within a region those variables are constant across LLS's.

The assumptions made above are rather standard when considering different

\footnotetext{
${ }^{5}$ The weakest assumption needed is that the growth rates of wages for a sector across LLS's are equal.

${ }^{6}$ This assumption is as in Barro [1].
} 


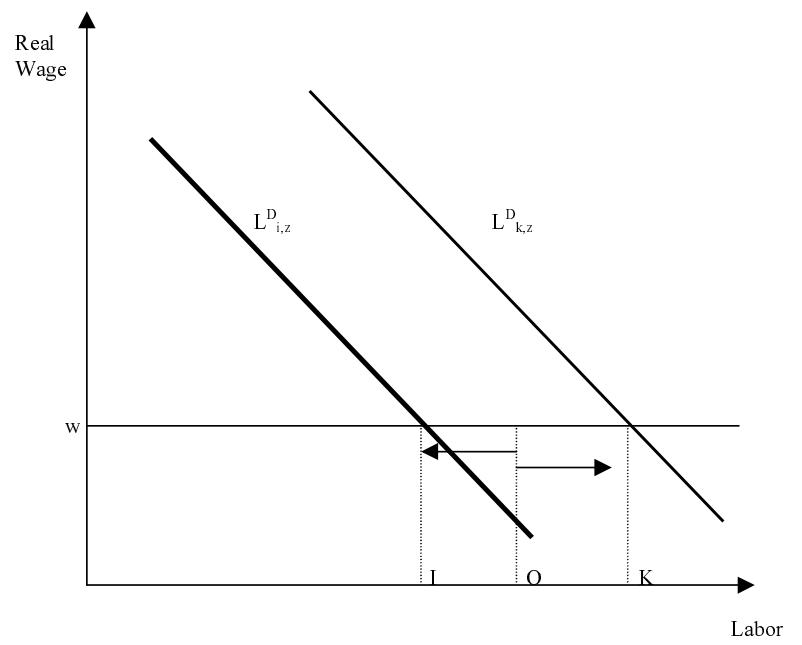

Figure 4: Labor Market in Industry-LLS

regions within a country. In particular the assumption of real wage equalization, implied by centralized wage setting, should not be too controversial. For the Italian case, there has been a debate on the evolution of north-south wage differentials and their influence on regional differences in labor creation. Unfortunately there is not enough consensus on the quality of regional wage data to include this variable in our analysis. Nevertheless, the assumption of equal growth rate of wages across Italian regions during the fifteen years considered seems to find support in several studies ${ }^{7}$.

Given the above assumptions and assuming, only for illustrative purposes, LLS's of identical size ${ }^{8}$ the long-run labor demand of an industry $z$ in LLS $i$ can be represented by the downward sloping curve $L_{i, z}^{D}$ in Figure 4 . Labor supply, assuming equalization of real wages, is just an horizontal line. The position of the demand curve depends on the relative productivity of the LLS/Industry; therefore two LLS/Industries with identical productivity will exhibit identical labor demand. Three main factors determine relative productivity: local agglomeration externalities, technology and local public capital.

Consider the demand for labor in sector $z$ and LLS $k$, represented by $L_{k, z}^{D}$ in the figure, and assume it is larger than the average demand $L_{i, z}^{D}$ because, say,

\footnotetext{
${ }^{7}$ Ginzburg et al. [17] summarizes this literature, referring in particular to Capparucci [5], Casavola et al. [7], Ferrero and Invernizzi [14]. See also the data reported in fig $2 \mathrm{~A}$ of the appendix of Casavola and Sestito [6].

${ }^{8}$ In the empirical analysis we measure employment of LLS's as Employment per unit of area. In so doing we account for the different size of LLS's.
} 
local externalities for sector $z$ are stronger in LLS $k$ than in the average LLS $i$. This means that, for sector $z$, location $k$ is better than the average $(i)$. If we assume a historically determined initial level of employment in sector $z$, both in location $k$ and $i$, and suppose that only in the long run will labor demand effectively determine employment, the growth of employment in LLS's $k$ and $i$ will be determined by the difference between the initial position and points $K$ and $I$, respectively. In particular, if employment is initially at point $O$ for both LLS's, then employment will increase in $K$ for LLS $k$ and shrink in $I$ for LLS $i$, as shown in the picture. On the other hand, if employment is already in $I$ for LLS $i$ and $K$ for LLS $k$, no new jobs will be created in either LLS. This shows that both local externalities (positively) and the initial employment (negatively) affect the growth of employment for an LLS/Industry.

Similarly, differential technological progress and differential growth rate of local infrastructures will shift the productivity of LLS's and move the labor demand curves accordingly. In the long run, employment will follow these factors, generating different rates of job creation across LLS's for each industry. Therefore our empirical strategy is to consider employment growth in LLS/industries as the dependent variable and, controlling for the initial level of employment, regress it on local agglomeration economies at the beginning of the period, as well as on measured regional technological progress and on regional growth of infrastructures.

As we are interested in the cross-LLS variation (rather than the crossindustry variation) all variables are taken in differences from the sector's national average and the estimates are done using only the between-LLS variation in job creation and not the within-LLS variation across industries ${ }^{9}$. The relationship implied by the model described above is:

$$
\begin{gathered}
\log \left(l_{z i}\right)_{t_{1}}-\log \left(l_{z i}\right)_{t_{o}}= \\
=a+\beta_{1} \log \left(l_{z i}\right)_{t_{o}}+\beta_{2}(\text { Aggl.Econ. } z i \\
)_{t_{o}}+\beta_{3}\left(\text { Tech.Change } \text { zrr }_{r}\right)_{t_{o}}+\beta_{3}\left(\Delta G_{r} .\right)
\end{gathered}
$$

The left hand side is the growth rate of employment in sector $z$ and LLS $i$, calculated as the logarithmic change of $l_{z i} . l_{z i}$ is employment per unit of area (density of employment); we standardize for the LLS area to adjust for the fact that different LLS's have different sizes. As fixed local factors (such as land) induce decreasing returns, the relevant initial condition is the initial density of employment rather than the initial absolute value of employment which could

\footnotetext{
${ }^{9}$ Namely averaging these differentials over sectors within LLS.
} 
vary across LLS just due to differences in their areas ${ }^{10} \cdot a$ is a constant, $\beta_{1}$ is a sort of "convergence" coefficient, and controls for the fact that, other things equal, higher initial employment (density) is associated with less labor creation. $\beta_{2}$ captures the effect of agglomeration economies; the explanatory variables we use should capture the three most important sources of local externalities. Finally, the last two terms, measured at the regional level, capture the impact on job creation of technological progress and of infrastructure improvements. Loosely speaking, the regression we estimate can be considered as a "growth regression" in which we are trying to explain growth in employment rather than growth of per capita GDP. Before presenting the results of the econometric analysis, let us explain in some detail our measures of local agglomeration economies, technological progress and public capital.

\section{Determinants of Job Creation}

The economic geography literature suggests that various kinds of production externalities may increase the productivity of local industries ${ }^{11}$. These externalities, which would induce differences in wages, across countries (as in Krugman and Venables [19]), will induce differences in employment growth across regions if growth of wages is equalized by the national institutions. Building on this insight we look into the effect of agglomeration economies in determining differentials in job creation. Following Marshall [26], we identify three kinds of local determinants of agglomeration externalities: backward and forward linkages due to transport costs, labor pooling externalities, and technological spillovers.

Given that externalities are not the only determinants of local productivity growth, we also make an effort to measure (at least at the regional level) technological progress using a frame that accounts for the multiplicity of sectors. We also consider the effect on employment of improving local infrastructures; for this purpose we use the measures developed by Picci and Bonaglia [30] on several stocks of infrastructures to assess their growth and impact on employment.

\subsection{Measuring External Agglomeration Economies}

Following Dumais et al. [12], we consider measures of the three most important agglomeration externalities (as already identified by Marshall [26]) that should induce firms to locate in one place (i.e. to create jobs in one LLS). We consider local characteristics at the beginning of the period as the pre-determined variables which affect the intensity of externalities and the long run labor demand during the period. Positive agglomeration externalities generate and maintain productive advantages for some industries in a location making them creator of larger number of jobs.

\footnotetext{
${ }^{10}$ Notice that, as the area of an LLS is constant over time, the growth rate of $l_{z i}$ is both the growth rate of density and of employment.

${ }^{11}$ See Fujita et al. [15].
} 


\subsubsection{Backward and Forward Linkages}

The first reason to have agglomeration economies in a location is the presence of potential suppliers and customers. Locating near potential customers and suppliers reduces transportation and information costs, and therefore increases the productivity of factors (labor) in that sector. For each industry $z$ in location $r$ we construct a measure of the fraction of national potential suppliers and customers that are located in the area. This measure captures the potential intensity of linkages (and of their pecuniary externalities) of industry $z$ in region $r$. The index constructed for the backward linkages is:

$$
\text { Input }_{z r}=\sum_{j \neq z} I_{j z} \frac{l_{j r}}{l_{j}}
$$

where $I_{j z}$ is the share of industry $z$ 's inputs coming from industry $j$, while $l_{j r}$ is the total employment of industry $j$ in region $r$ and $l_{j}$ is total employment of industry $j$ nationwide. The input coefficient $I_{j z}$ is taken from the national Input-Output matrix; the above index is 0 if no potential supplier is located in the same region, and 1 if all of them are.

The index that captures forward linkages is defined as follows:

$$
\text { Output }_{z r}=\sum_{j \neq z} O_{j z} \frac{l_{j r}}{l_{j}}
$$

where the $O_{j z}$ is the share of industry $z$ 's output going to industry $j$, taken from the national input-output matrix. These two indices should affect the employment growth of an industry in one location positively. They are constructed including not only the industries in the same LLS as potential suppliers and customers, but all the industry in the region which are considered as potential customers and/or suppliers by one LLS/industry. This implies that we consider the region around an LLS as its natural local market ${ }^{12}$ and that, for each industry, all LLS's in the same region have the same input and output linkages. Moreover, as these two indices are rather collinear, in our regressions we include In\&Out which is the average of the two indices (rather than each one separately), to capture input-output linkages together.

\footnotetext{
${ }^{12}$ A more accurate procedure to measure "local market" linkages would be to include industries in LLS within a certain radius from the LLS considered, rather than those in the same region. We have not implemented this measure, so far, as it implies very cumbersome code-writing.
} 


\subsubsection{Labor Market Pooling}

A second reason generating agglomeration externalities is known as labor market pooling. Workers with certain skills are more willing to move to a local labor market in which a large number of firms, demanding these skills, is present, since this offers them some insurance in case of dismissal, and also more bargaining power after having acquired some specific human capital ${ }^{13}$. Reciprocally, firms will be willing to locate in areas where they can find a set of workers' skills similar to the one preferred because during booms they could hire more of the local workers. Therefore firms will create more jobs in localities whose skill composition is similar to their preferred one. The existence of a local pool of worker similar to the one preferred by an industry should therefore generate this type of externality, encouraging firms of that industry to locate there. The index of labor pool similarity for industry $z$ in LLS $i$ is:

$$
\operatorname{LabMix}_{z i}=-\sum_{o}\left(l_{z o}-\sum_{j \neq z} \frac{l_{j i}}{l_{i}} l_{j o}\right)^{2}
$$

where $l_{z o}$ is the share of employed in occupation (skill) $)^{14} o$ in sector $z$, measured nationwide. The summation in brackets reconstructs the potential local pool of workers by occupations (skills), inferring them from the sector composition of the LLS and attributing to each local industry the national composition by occupation of that industry. The index is a "distance index" between the preferred skill-composition of an industry (i.e., its average composition) and the local skill composition, inferred from the local industrial mix. As we take it with a minus sign we expect an increase in this index to reflect larger externalities from labor pooling, for a local industry and therefore a stronger potential for labor creation.

\subsubsection{Technological Spillovers}

Geographical proximity may generate technological spillovers. These spillovers are the benefits accruing to a firm because knowledge spreads easily in the local environment and firms may have an advantage in imitating or following the procedures of their neighbors. These spillovers would be maximized by proximity with industries which generate a large amount of useful flow of knowledge. The index we construct is based on a technological input-output matrix, estimated by Scherer [31] for the US, and relative to the 80's. Using data on patents, Scherer assess the amount of technological production of a sector that benefits another sector. In particular, the "source" sector is identified as the sector

\footnotetext{
${ }^{13}$ See Dumais et al. [12] for references

${ }^{14}$ The occupations defined in the 1981 census are 12 , while in 1991 and 1996 they are 9. These occupation are such as: "clerical worker", "generic blue collar", "specialized blue collar", "technician", "business administrator" and so on.
} 
which has spent R\&D resources to lead to the innovation, while the "receiver" sector is identified as the sector using the innovation generated by this R\&D.

The nature of inter-industry spillovers may be different across countries and periods. Therefore this measure is at best a proxy of the local technological spillovers in Italian local labor systems, given that it has been calculated using US input-output technological flows. Using these coefficients enables us to build an index similar to those measuring input-output linkages, which now captures the potential technological spillovers in an LLS for a certain industry. The index for industry $z$ in LLS $i$ is:

$$
\text { Techflow }_{i z}=\sum_{j \neq z} T_{j z} \frac{l_{j i t}}{l_{j t}}
$$

where $T_{j z}$ are the shares of innovative R\&D flowing to industry $z$ from industry $j$ estimated by Scherer [31] while the other variables are defined exactly as in formulas 2 and 3 . The only difference, now, is that we consider only firms within the same LLS, as we believe that the most relevant technological spillovers take place via personal interactions and therefore they remain very localized.

Given their definition, if the externalities described by Marshall are at work in determining the productivity of a geographical unit, the indices described above should have a positive effect on employment growth. Some locations exhibit larger linkages and technological spillovers as well as more diversified skills than others. This should provide stronger external economies for firms which locate there, encouraging larger labor creation.

\subsection{Measuring Technological Progress}

Although a crucial and often invoked variable in policy analysis, technical progress tends to be hard to measure. Using the "Solow residual" to capture it could be more appropriate for cross-regional analysis than for cross-country analysis, because of the higher degree of homogeneity of several unobservables across regions rather than across countries. Difficulties arise, though, in constructing all the variables needed to compute it accurately. Among other problems, capital stocks tend to be constructed under very strong assumptions and are subject to important measurement-error problems, and reliable factor-income shares are even harder to find. Here we briefly describe the intuition on how to construct an approximation to regional TFP growth rates without using data on capital stocks and factor-income shares. For the details on this procedure and for the formulas used we refer to Appendix A2.

The basic idea used in this procedure is that, under suitable assumptions, one can infer the approximate behavior of TFP growth from value added growth and the factor allocation pattern of an economy. Considering the growth in value 


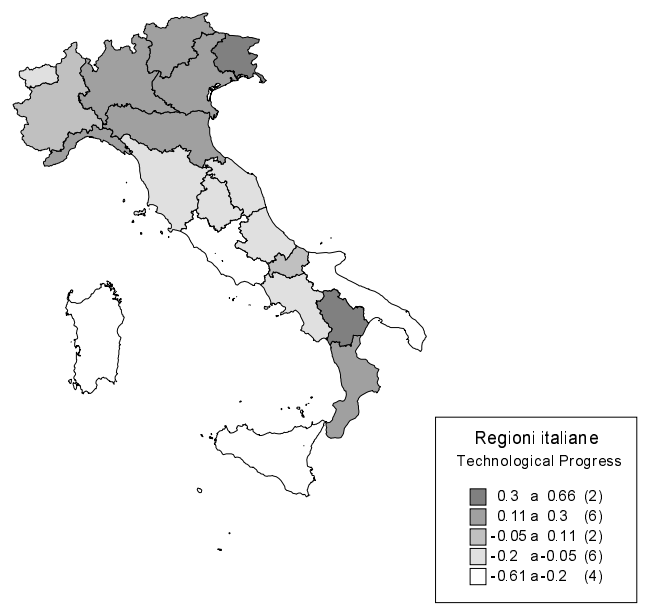

Figure 5: Estimated Regional Technological Growth: Yearly growth rates

added per worker in one region, we can decompose it in a term which is due to labor reallocation across sectors, and one due to increased labor productivity of the regional sectors. Under the assumption that the wage-rental ratio grows at the same rate across regions, if each sector has the same production function across regions, regional differences in the growth of labor productivity (second term of the decomposition), are essentially due to differences in TFP growth. To derive "TFP" growth in this way we also need to adjust for the sector-composition of a region. Having done that we obtain measures of regional technological progress as differences of regional factor-augmenting technological growth from the national average. The main advantage of this strategy is that the variables on which the TFP measure is based are less affected by measurement error. Our results, nevertheless, have to be interpreted with some caution as our TFP measure does not account for human capital accumulation as we do not have data on schooling. Due to data availability, the finest level of geographical disaggregation with which we can construct TFP-growth rates is that of Italian regions.

Figure 5 reflects TFP growth differences across regions for the period 19811996, measured as yearly percentage increases. A darker color has to be read as a larger difference between regional and Italian TFP growth rates. Once again, the Northeast is the best performer, far above the rest of Italy. As for the rest of the country, the Northwest performs more or less like the Italian average or slightly better, whereas almost all of the South does rather poorly (far below the Italian average). Two exceptions to this trend are Basilicata and Calabria. Basilicata derives its good performance from a relatively high growth of value 
added per worker, while for Calabria the effect is due to small reallocation, especially when measured at the average national industry-composition.

\subsection{Measuring Public Capital}

Improvements of local infrastructures, especially those affecting communication and transport, should be the another important determinant of local productivity. First, infrastructures are important productive inputs which could substantially enhance the efficiency of labor. It is not by accident that the Delors Report (1989) and then the whole policy of European Structural (regional) Funds emphasizes the provision of infrastructures as a pre-requisite for development. Also, more recently (1998-2000), in the so called "New Policy Planning" (Nuova Programmazione or simply NP) the Italian Government has emphasized the role of public investment in infrastructures as crucial long-run catalysts for the southern development ${ }^{15}$.

Second, if better connected within its region, a LLS could better exploit its local linkages and enlarge the market for its products, therefore the investment in communication infrastructures could be most effective when the LLS is in a region which offers rich linkages. This is why we consider the growth rate of public capital, and specifically of transportation and communication infrastructures, as one of the potential determinants of employment growth. The measure that we use is the aggregation of several different types of infrastructures, whose stock at the regional level has been calculated by Picci and Bonaglia [30]. We construct a measure of total infrastructures ${ }^{16}$, adding all the nine different kinds of public goods considered in Picci and Bonaglia [30], and then a measure that separates transport and communication infrastructures from all the rest.

Interestingly, confirming the analysis of Picci, the growth rate of total infrastructure as well as communication and transport infrastructures in the 19811996 period has been larger in the northern regions (with a small advantage of the Northeast: $+1.34 \%$ a year over the Northwest's $+1.10 \%)$ than in the Southern regions (where the Southwest+islands have had the lowest growth: $+0.68 \%)$.

As Figure 6 and 7 show, the increase of public infrastructure has concerned mostly the northern regions while the south, with the possible exception of Puglia, has shown remarkable sluggishness even on this regard. If improvements of infrastructures had a positive impact on employment, Northern Italy is the area which benefited the most from this channel.

\footnotetext{
${ }^{15}$ See Donzelli $[10]$.

${ }^{16}$ The kind of infrastructures considered are: Roads and Airports, Railways, Harbors and Canals, Communication plants for the "Transport and Communication" infrastructures, while Electrical and Idro-electrical plants, Public housing, hygienic structures and other public works are the other infrastructures.
} 


\section{yearly growth of public capital 1981-199}

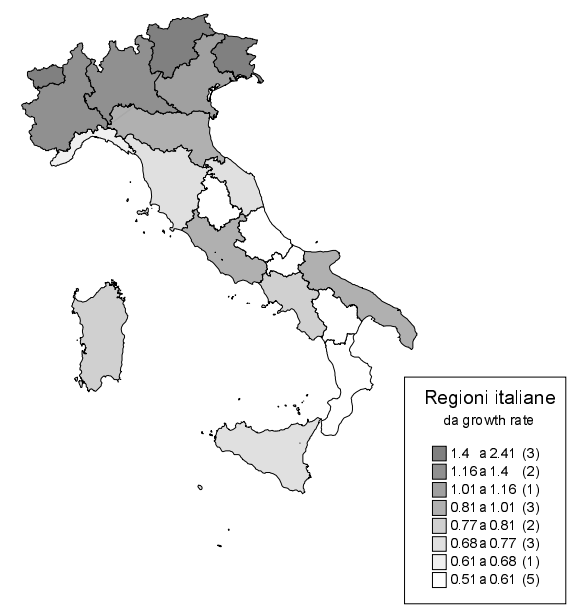

Figure 6: Growth of Infrastructures in Italian Regions

Yearly Growth of Transport-Communication Public Capital 1981-19

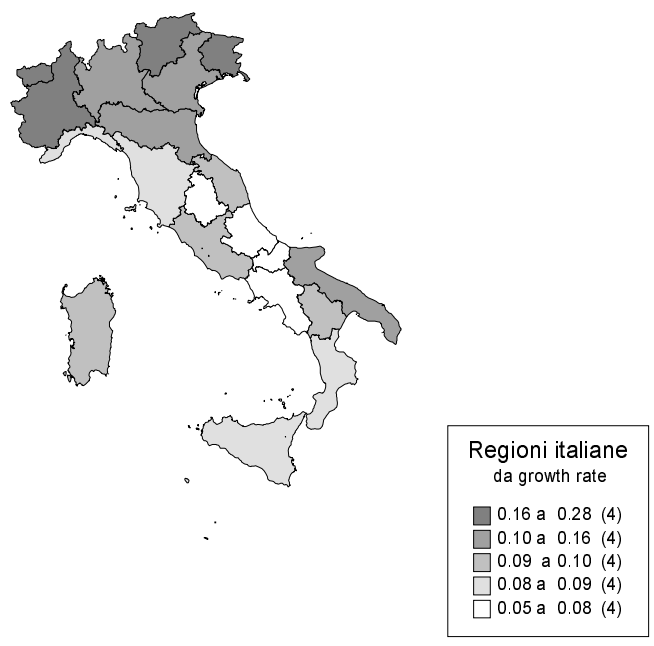

Figure 7: Growth of Transport-Communication Infrastructures in Italian Regions 
The slow growth of public infrastructures in southern regions is even more serious if we take into account the fact that the overall spending for public investments in Italy has decreased significantly, especially after 1991, due to budget cuts to achieve the Maastricht criteria. The strong negative shock due to the decrease in public spending is accompanied, if the cuts hit public investments, by a worsening of the long run productivity growth and job creation. This, more than the negative shock to aggregate demand, will certainly be a long lasting legacy of the fiscal retrenchment of the 90 's.

\section{$5 \quad$ Job Creation and its Determinants}

This section has two main goals. First, we intend to apply the econometric model described in Section 3, and estimate the effect on job creation of the variables discussed above. The second goal is to assess how much of the variation in the performance of each macro-area can be explained by these factors. The basic equation that we estimate is obtained from Equation ??: for each LLS/industry we take its difference with the national average for that industry and then average these differences over the 47 industries in each LLS, weighting each variable by the share of that industry in the LLS. We can represent the estimating equation as follows:

$$
\begin{aligned}
& \left.\overline{g_{t_{0} t_{1}}\left(l_{i}\right)}=a+\beta_{1} \overline{\log \left(l_{i}\right.}\right)_{t_{o}}+\beta_{2}\left(\overline{\text { In\&out }_{i}}\right)_{t_{o}}+\beta_{3}\left(\overline{\text { LabMix }_{i}}\right)_{t_{o}}+ \\
& +\beta_{4}(\overline{\text { TechFlow }})_{t_{o}}+\beta_{4}\left(\text { Tech. Growt } h_{r}\right)_{t_{0}}+\beta_{5}\left(g_{t_{0} t_{1}}\left(G_{r}\right)\right) \text {, }
\end{aligned}
$$

where $g_{t_{0} t_{1}}$ indicates the yearly average growth rate between $t_{0}(=1981)$ and $t_{1}(=1996)$. The variables with an upper bar have been taken in differences from the national industry average and then averaged within the LLS. The index $i$ denotes LLS's and varies between 1 and 784. The variables with an $r$ subscript are measured at the regional level. The regressors measured at the LLS level are initial employment (per unit of area), the initial value of LabMix (Equation 4), and the initial value of TechFlow(Equation 5). The initial value of In\&Out, the Input-Output index, obtained averaging 2 and 3, varies only across regions because we consider the whole region as potential market for a LLS/Industry. The last two regressors, measured at the regional level, are the imputed technological progress and growth in public infrastructures, described in Sections 4.2 and 4.3.

We use FGLS to estimate equation 6, so as to correct for heteroskedasticity due to differences in the size of LLS's. The results of the regressions are reported in Table 4. In order to interpret the magnitude of the estimated coefficients more easily we have standardized all variables: employment density (in $\log$ ) and the indices In\&Out, LabMix, TechFlow have been divided by their standard deviations, while all the growth rates (both of the dependent variable 
and of the independent variables) are expressed in yearly percentage values. Thus, the coefficients we report in Table 4 are "elasticities" (for technological progress and growth of public infrastructures) and quasi-elasticities (for the indices) expressing the percentage change of the dependent variable in response to a change in one standard deviation of the independent variables.

Table 4: Determinants of Job Creation

\begin{tabular}{|c|c|c|c|c|}
\hline Specification & $\overline{\mathrm{II}}$ & $\overline{\mathrm{II}}$ & 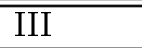 & $\overline{\mathrm{IV}}$ \\
\hline$\overline{\log \left(l_{i}\right)}$ & $\begin{array}{c}-0.47^{*} \\
(0.03)\end{array}$ & $\begin{array}{c}-0.47^{*} \\
(0.03)\end{array}$ & $\begin{array}{c}-0.45^{*} \\
(0.04)\end{array}$ & $\begin{array}{c}-0.45^{*} \\
(0.04)\end{array}$ \\
\hline$\overline{\text { In\&out }_{i}}$ & $\begin{array}{l}0.23^{*} \\
(0.04)\end{array}$ & $\begin{array}{l}0.18^{*} \\
(0.04)\end{array}$ & $\begin{array}{l}0.15^{*} \\
(0.04)\end{array}$ & $\begin{array}{l}0.18^{*} \\
(0.04)\end{array}$ \\
\hline$\overline{\operatorname{LabMix}_{i}}$ & $\begin{array}{l}0.11^{*} \\
(0.05)\end{array}$ & $\begin{array}{l}0.10^{*} \\
(0.05)\end{array}$ & $\begin{array}{c}0.09^{*} \\
(0.046)\end{array}$ & $\begin{array}{c}0.09^{*} \\
(0.041)\end{array}$ \\
\hline$\overline{\text { TechFlow }_{i}}$ & $\begin{array}{l}0.012^{*} \\
(0.006)\end{array}$ & $\begin{array}{c}0.012 \\
(0.007)\end{array}$ & $\begin{array}{c}0.010 \\
(0.007)\end{array}$ & $\begin{array}{c}0.010 \\
(0.008) \\
\end{array}$ \\
\hline Tech. Growth ${ }_{r}$ & & $\begin{array}{c}0.44^{*} \\
(0.16)\end{array}$ & $\begin{array}{l}0.30^{*} \\
(0.15)\end{array}$ & $\begin{array}{c}0.25 \\
(0.15)\end{array}$ \\
\hline$g_{t_{0} t_{1}}\left(G_{r}\right)$ & & & $\begin{array}{l}0.24^{*} \\
(0.07)\end{array}$ & $\begin{array}{c}0.28^{*} \\
(0.12)\end{array}$ \\
\hline$g_{t_{0} t_{1}}\left(G_{r}\right)-$ NonTransport- & & & & $\begin{array}{l}-0.05 \\
(0.07)\end{array}$ \\
\hline Obs. & 784 & 784 & 784 & 784 \\
\hline$R^{2}$ & 0.31 & 0.32 & 0.33 & 0.33 \\
\hline \multicolumn{5}{|l|}{ Dependent Variable: $\overline{g_{t_{0} t_{1}}\left(l_{i}\right)}$} \\
\hline Std. Errors in Parenthesis, ${ }^{*}=$ & iifican & level & & \\
\hline
\end{tabular}

Specifications I to IV in Table 4 include progressively more of the determinants of job creation we have described. Regression I considers only the local determinants, which explain about one third of the cross-sectional variation in job creation across LLS's in terms of the $R^{2}$. We see that denser LLS's exhibit a disadvantage in creating new jobs. This confirms that there is a tendency of employment density to converge to a balanced growth path level for given local economies of agglomeration. This convergence term seems important to explain the lower creation of jobs in the "western" part of the country, which is more dense than the eastern part. It also helps explain why small and medium-size LLS's have done better than the large urban areas.

Moreover, specification I shows the positive and significant impact of inputoutput linkages and of the local pool of workers in creating new jobs. In quantitative terms, the strongest effect is due to local linkages: a LLS that provides stronger linkages for its industries by one standard deviation generates around $0.20 \%$ more growth of employment per year. The difference between the least "linked" and the "most linked" LLS (about 5 std deviations) could be responsible for $1 \%$ difference in labor creation per year. Also the Labor Market variable 
is important, and its effect is around half as big as the Input-Output one: a LLS which has a local pool of workers with diversified skills or, in any case, with skills in higher demand, will be attractive to a larger number of producers and will create more jobs.

The variable that captures local technological flow, although close to statistical significance, is quantitatively rather small. This result may be due to the fact that the measure of technological flows in Italy could be different from those obtained using US data; also, part of these flows may be captured by the input-output linkages or by skills similarities. A confirmation of this hypothesis comes from the following fact: if we omit the Input-Output index, the coefficient of the variable TechFlow doubles and becomes significant. It is also possible that the Italian industrial composition is more shifted towards traditional sectors if compared to the US, and therefore less affected by technological spillovers. Finally we have tried adding the Input-Output index calculated including only industries within each LLS as potential customers-suppliers. We get that the coefficient of the "region-wise" In\&Out is almost unchanged $(0.24$, with std. error 0.04) while the "LLS-wise" In\&Out linkages are not significant. This suggests that the relevant local input-output linkages spread beyond the $\mathrm{LLS}^{17}$.

Specification II includes the imputed technological change as a regressor. The coefficient on this variable is large and significant. It is interesting to notice that when we include infrastructure growth, the coefficient on the technological change term decreases sensibly and become less significant. Regressions III and IV show the important role of infrastructure development for labor creation. In particular, the growth of transport and communication infrastructures is quantitatively very important for employment growth: an increase of that growth rate by one percentage point per year raises employment growth by $0.28 \%$ a year. Once we control for transport infrastructures other infrastructures seem to have little or no impact on job creation.

We have also tried to interact the two terms capturing regional input-output linkages with the growth of transport infrastructures. This helps us check whether transport infrastructures favor local productivity by improving the connections of the LLS with its region and potential customers and suppliers . The coefficient estimate for this interaction term ${ }^{18}$ is large and significant $(+0.51 \%$ for one standard deviation with a standard error of $0.16 \%$ ), while the coefficient on the In\&Out coefficient drops almost to zero, and the coefficient on the growth rate of infrastructure drops to $0.17 \%$ (std. error $0.08 \%$ ) when including the interaction. This confirms that a main channel of effectiveness of transport infrastructures is that they connect the LLS's within a region. Summarizing, the local factors and technological progress plus infrastructure explain around

\footnotetext{
${ }^{17}$ We have tried the same with the Labor Mix index, but in this case the region-wise index is never significant. This makes us confident that the LLS is the relevant unit as far as labor market characteristics are concerned.

${ }^{18}$ This regression is not reported in the tables.
} 
one third of the cross-sectional variation of job creation, they are therefore important determinants of these cross-LLS differences.

Let us now shift gears and consider whether the same explanatory variables can help explain the variation in employment growth across Italian macro-areas. To do so we consider a regression with the same dependent variable as in Table 4 (average job creation in each LLS in deviations from the sectors' average), and include as regressors four regional dummies (Northeast, Center, Southeast, Southwest+islands). The coefficients on these dummies are estimates of the average differentials in job creation across the macro-areas. Specification 0 in Table 5 contains only the dummies as regressors, while I-IV are identical to I-IV in Table 4 as they include, respectively, the same regressors on top of the four dummies. In Table 5 we only report the coefficient of the dummies and the summary statistics of the regressions. The coefficients on the single regressors for each specification (not reported) are very similar to those reported in Table 4.

TABle 5: Explaining Macro-Areas VARiation

\begin{tabular}{lccccc}
\hline \hline Macro-Area & 0 & I & II & III & IV \\
\hline \multirow{2}{*}{ Northeast } & $0.52^{*}$ & $0.36^{*}$ & $0.31^{*}$ & $0.31^{*}$ & $0.30^{*}$ \\
& $(0.13)$ & $(0.13)$ & $(0.13)$ & $(0.13)$ & $(0.13)$ \\
\hline \multirow{2}{*}{ Center } & 0.00 & -0.12 & -0.11 & -0.11 & -0.09 \\
& $(0.11)$ & $(0.12)$ & $(0.12)$ & $(0.12)$ & $(0.14)$ \\
\hline \multirow{2}{*}{ Southeast } & $0.45^{*}$ & $0.38^{*}$ & $0.43^{*}$ & $0.42^{*}$ & 0.48 \\
& $(0.18)$ & $(0.18)$ & $(0.18)$ & $(0.20)$ & $(0.27)$ \\
\hline \multirow{2}{*}{ Southwest-Islands } & -0.12 & -0.14 & -0.13 & -0.07 & -0.02 \\
& $(0.12)$ & $(0.12)$ & $(0.12)$ & $(0.18)$ & $(0.20)$ \\
\hline Obs. & 784 & 784 & 784 & 784 & 784 \\
\hline$R^{2}$ & 0.04 & 0.34 & 0.35 & 0.35 & 0.35 \\
\hline Dependent Variable: & $g_{t_{0} t_{1}}\left(l_{i}\right)$ & Regressors in Specification I-IV are as in Table 4 \\
\hline Std. Errors in Parenthesis
\end{tabular}

The analysis of the coefficient on the dummies helps us understand which factor contributes most in the explanation of the cross-regional differences in job creation $^{19}$. In particular, for each regressor we can observe the change in the dummies' coefficients due to the inclusion of that control. If our regressors fully explain the variation of employment behavior across macro areas, once we have controlled for them the coefficient on the dummies should all be zero. If they do not explain any of the macro-areas variation then the dummies coefficients will not change after including them. In other words, the decrease in the absolute value of the estimates of the area dummies' coefficients is a reduction of "our ignorance" on the causes of differential job creation in the five Italian macroareas, that have performed so differently in terms of job creation.

\footnotetext{
${ }^{19}$ This method of analyzing changes in "fixed effects" when including controls is used in Kolko [20].
} 
Table 5 reports the estimates that capture the difference in job creation of each macro-area with the Northwest. We begin by including no regressors besides the dummies (0), then we include the local agglomeration characteristics (I), the local characteristics plus technological change (II), and finally those variables plus infrastructure (III), or plus infrastructure divided into transport and non-transport (IV $)^{20}$. The last column is "the best we can do" in explaining the differences using our regressors. It shows a substantial decrease of the coefficients on Northeast and Southwest, while a small (non significant) increase in the coefficients of Center and Southeast. Putting these results in words, the structural factors considered provide a good explanation for about half of the advantage of the Northeast in creating jobs and for almost all the disadvantage of the Southwest in creating jobs (both relative to the Northwest). Interestingly, the Northeast is the only area which significantly differs from the rest in job creation after controlling for the structural factors. That is, the Northeast performs significantly better than its characteristics would predict.

More specifically, if we consider the contribution of single factors to the explanation of different performances, we observe that local agglomeration economies are responsible for a sizable part of the Northeast's advantage (almost one third) while slow infrastructure growth seems to explain the bad performance of the Southwest. Interestingly, local characteristics also seem to contribute to explain part of the Southeast's good performance, but technological progress and infrastructure growth more than offset this effect, leaving the Southeast coefficient unexplained (although it is measured with a large standard error).

Again, overall we are left with a partial explanation for the differentials in job creation even across macro-regions. In particular, the factors identified seem to explain better the different performances of the Northeast and the Southwest rather than those of the other macro-areas. Nevertheless, in this case we have singled out two important factors to explain the good performance of the Northeast (the best performer in Italian job creation) and the bad performance of Southwest (the worst performer). Namely Northeastern regions have been helped in job creation by their local characteristics: low initial density of employment, strong local input-output linkages, local mix of labor and technological spillovers, while the Southwest has been particularly damaged by the lack of infrastructure growth.

\section{Perspectives and Policies}

Sections 3 and 4 of the paper have focused on the determinants of labor demand at the local and regional level, estimating their impact on job creation. Our claim has been that local determinants of productivity are key in understanding differential rates of job creation in an economy with centralized labor

\footnotetext{
${ }^{20}$ The order in which we add regressors might affect the contribution of each one in explaining regional differences. We have tried, though, different ordering and the qualitative results do not change.
} 
market institutions (and subsequently relatively homogenous wages). General "labor market policies" that apply in all regions do not address specifically the problem of within country disparities and the Mezzogiorno problem. However, a potential benefit of policies allowing for a less regulated labor market is that they might induce decentralized wage bargaining. This would affect job creation positively by decreasing the cost of labor in disadvantaged areas. Our work does not provide insights on the impact of such measures on job creation, since we have assumed wages growing at a common rate nationwide. It certainly provides enough evidence, though, that important determinants of labor demand are local and very different within the country. This implies that centralized conditions of labor supply will favor differences in job creation, participation, and unemployment rates across regions.

Indeed, the insight of our results is deeper than that. By considering the local determinants of labor productivity we are dealing with some key determinants of regional disparities. The fact that these disparities translate into differential job creation or differential wage growth depends on the labor market institutions. In either case, though, if we do not observe large mobility of workers, these differences will translate in different growth of GDP per capita across regions. Policies aimed at tackling regional unbalances should consider the productivity determinants discussed above as important "supply side" factors of local competitiveness. If the productive environment and competitiveness are the main determinants of job creation as well as of GDP growth in the long run, these factors should be object of careful consideration.

In this section we provide a view of the potential of Italian LLS's, as predicted by our analysis, in order to help identify the appropriate policies and to assess the performance of local economies in the coming decade. We use the estimates obtained from Section 4 and update the measures of agglomeration characteristics. In particular, stretching somewhat the assumptions made in that section, we consider the measured characteristics of LLS's (density, inputoutput linkages, labor market mix of skills and technological linkages) in 1996 as predetermined variables for the following period. These characteristics should affect job creation in the following fifteen years (just as they did in the previous fifteen). Needless to say, these local characteristics have changed also because of economic growth in the recent decades; if growth is correlated over time, we have a problem of endogeneity. Nevertheless, with all the cautions that the interpretation of the results should involve, we consider this analysis rather informative. It provides a picture of where different LLS's stand, currently, in terms of potential for job creation (or for wage growth if more wage flexibility will be allowed).

As we have the updated data for 1996 (ISTAT [23]), we measure $\log \left(l_{i}\right)$, In\&Out, LabMix and TechFlow for each LLS in the same way as we did for 1981. Then we construct the "potential" for job creation using the estimated impact of those variables in regression IV (Table 4), and also adding the estimated 
regional dummies ${ }^{21}$, while we assume equal growth of technology and infrastructures across regions. Clearly the results will be informative about the deviation of this constructed variable from its average ${ }^{22}$. Given the local characteristics of 1996 and their estimated impact, we are able to assess how different will be the potentiality for job creation across LLS's for the next decade, assuming equal technological growth and equal public investment across regions.

This exercise should not be taken as a forecast. It is rather a way to present the data on recent (1996) characteristics of the LLS's, as some of them have changed importantly since 1981, through a synthetic index which gives more weight to those characteristics which have been more important in creating jobs during the 1981-1996 period. The resulting index of "potential job creation" measures the potentiality for employment growth (in percentage points) implied by the observed initial characteristics of the LLS's.

A first way of summarizing the data consists simply in reporting this index of "job creation potential" on a map (Figure 8 ), averaging LLS's across provinces ${ }^{23}$ and indicating higher potentials with darker colors. We standardize the average to 0 and obtain that potential job creation range from $-0.73 \%$ to $+0.66 \%$ a year. The standard deviation of provincial potentials is $0.30 \%$ per year. This province-representation conceals a larger variation at the LLS's level; in fact, the standard deviation of LLS's distribution of job creation potentials is $0.55 \%$, while the highest potential is $1.3 \%$ and the lowest is $-2 \%$.

Viewing the map we find two areas where strong potentials are concentrated: eastern Lombardia plus Veneto-Friuli and Trentino, and the southeastern area of South-Abruzzo plus northern Puglia. The Center and the Northwest do not show very strong potentials, while the Southwest seem rather good. The reasons for this distribution need to be analyzed in more detail. An apparent fact is that provinces containing large (dense) cities appear very disadvantaged: Milano, Torino, Napoli, Firenze and Bologna appear among the worst performers as they are strongly affected by the fact that higher density of employment penalizes job creation (and rather heavily given the estimates of $-0.45 \%$ from specification $I V$ in Table 4). Also, large part of the Northwest's disadvantage and the South's advantage is driven by the fact that the first area has high density of employment while the second has low density. Given that our regression analysis implies convergence in employment density, southwestern job creation potentials benefit from this gap.

Nevertheless, the different performance in the South, where Abruzzo, northern Puglia and northern Campania (except for the Napoli-Salerno area) show better potential than Calabria, Basilicata and Sicilia, depend crucially on local

\footnotetext{
${ }^{21}$ In so doing we assume that those "unexplained factors" differring across macro-area are rather persistent. They could be linked to endowments of human and social capital which we do not observe.

${ }^{22}$ We are unable to say anything on average job creation.

${ }^{23}$ Since many LLS's cross provincial borders we have assigned one LLS to the province in which it has its largest part of employment.
} 


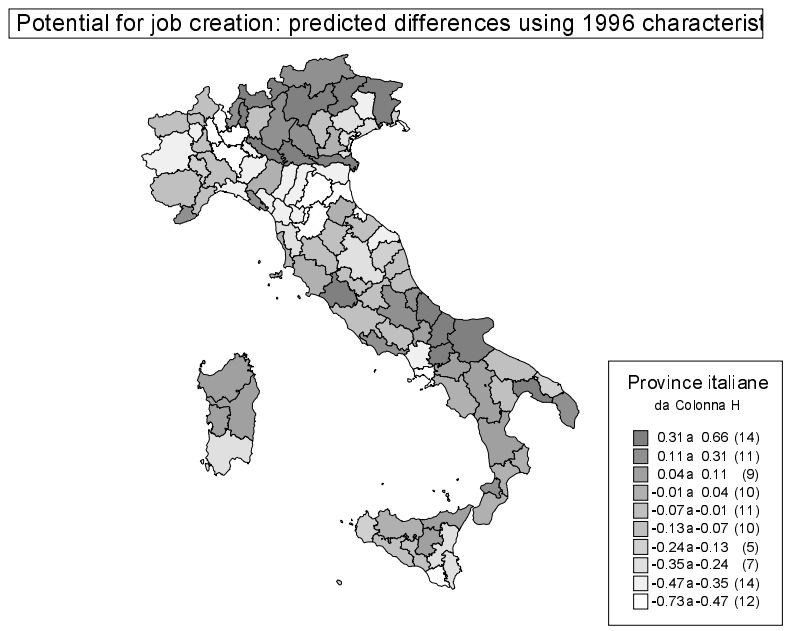

Figure 8: Potential for Job Creation in Italy, 1996

characteristics. It is useful, therefore, to show the map with differences in employment potential due only to agglomeration characteristics (In\&Out, LabMix and TechFlow) leaving out the dummies and the density effect. Figure 9 shows the differential of job creation potential predicted using only the three agglomeration measures weighted with their coefficient estimated in specification IV (Table 4). Local labor linkages, labor markets and technological flows benefit the North (mostly Lombardy and Veneto) and Latium (because of Rome as a local market), while in the south Abruzzo, Puglia and northern Campania (not Naples) have an advantage over Calabria, Basilicata and Sicilia.

Looking at the single LLS's potentials, the very best are concentrated in the provinces of Chieti and Foggia (Biccari, Candela, Bovino, Serracapriola and Crecchio are the top five LLS's) while the best LLS's considering only local agglomeration economies are in Lazio and Lombardia (Frosinone, Aprilia, Rieti, Sondalo, Castelforte). On the other end of the range, when we consider local agglomeration forces only, the worst LLS's are in Calabria (Forio, Tropea, Nocera Terinese, S. Lucido), while for the overall performance the large metropolitan areas such as Milano, Torino and Napoli have the direst perspectives, due to their very high density of employment.

Reading the results with a grain of salt, we summarize them in the following points:

- The Northeast still appears the most promising area, partly because of its local characteristics, and partly because it is still less densely populated 


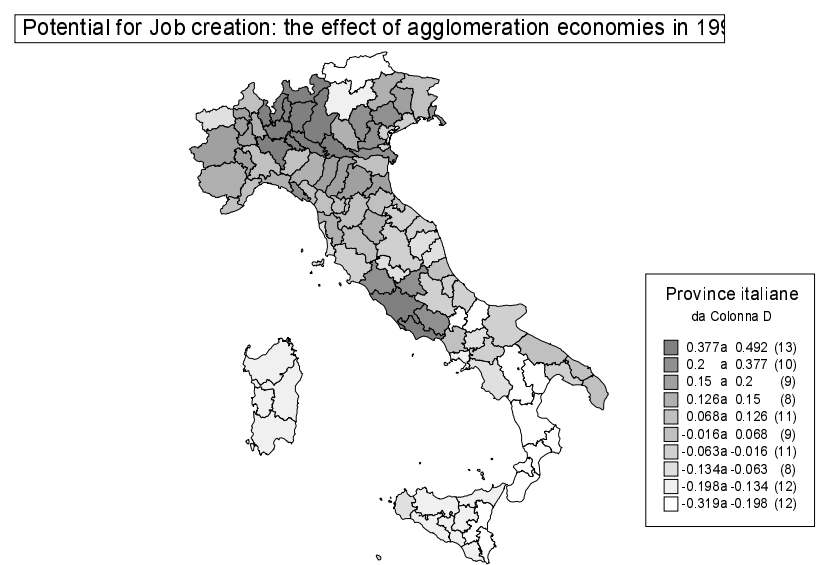

Figure 9: The contribution of Agglomeration Economies

than the Northwest. Part of its good performance is left unexplained; we conjecture it may be linked to the good qualities of its local institutions, social and human capital

- The Southeast, in particular southern Abruzzo, and the provinces of Benevento in Campania and Foggia in Puglia, is the most promising area in the South. These areas combine good local market characteristics, proximity to Rome, and a gap that makes them ready for "take-off".

- The Southwest, in particular Calabria, Basilicata and Sicilia have mostly "non-exploited opportunities" ahead (as well as in their recent past). Still lagging behind in terms of local economic network and recently penalized by the slowdown in public investments, they have a large gap to fill. This gap, in the event of a "take-off" (as part of the Southeast is doing), will grant them years of sustained catch-up growth. Currently, though, few signs of this take-off are visible.

- The size of the differences in job creating potentials implied by the local characteristics are large but not dramatically so. The estimated large impact of infrastructure growth on job creation could be one way to reequilibrate it. Higher growth of public transportation infrastructure by one percent a year would fill a difference of $0.30 \%$ in job creation, which is one standard deviation of the distribution of province estimated potential. There is therefore scope for structural policies to contribute to fill the gap in job creation. 
The analysis proposed above could also be specialized to understand which sectors have larger potentials in which LLS's, as the measures obtained are specific to LLS/industry. This could also be important to design local policies to accompany and help successful industries or to redirect previously misplaced public policies. We leave this task to further research.

\section{Conclusions}

The present work has undertaken the task of carefully measuring job creation and its determinants in Italian Local Labor Systems, providing an explanation of their performance and an assessment of their future perspectives. Two are the main contributions of this paper. First, we organize data on employment by industry, taken from the 1981-1996 censuses, and develop measures of local agglomeration externalities at a very detailed geographical level for the whole country. In so doing we are able to test theories of local agglomeration and their impact on job creation with comprehensive "micro-data". Second, complementing these data with a regional analysis of technological progress and growth in infrastructures we assess the impact of these factors on differences in job creation across Italian macro-regions.

Few words should be said to confirm the fact that our analysis treats an important aspect of job creation rather superficially, namely the characteristics of labor supply. In particular we do not consider measures of human capital (schooling) in different regions, which is an important determinant of productivity and also of the probability of finding a job. A possible extension of our work should include some measures of the local level of schooling (although we would not be able to recover such measure for LLS's) to characterize local labor supply. In spite of this, we claim that by considering technological progress, agglomeration externalities and infrastructures we have included most of the important determinants of local productivity (and job creation) in the long run.

Even if the paper has been concerned with explaining job creation, we regard it as a contribution to understand Italian regional (and local) economic disparities, in general. In the last two decades, regional divergence in growth rates of GDP per capita in Italy has gone through the differences in employment/population evolution, rather than through differences in productivity growth. Successful regions have been so because they have been able to "put at work" a larger fraction of their population. Successes have been largely driven by local characteristics promoting the regions' (or the locations') competitiveness. This local advantage is the main determinant of long-run growth in income and employment in a geographic unit, be it a region or a LLS.

Borrowing from Economic Geography and Growth theories we have identified and measured some of the variables regarded as long-run catalysts of development, and we have proved and quantified their impact on job creation. We think that economic policy aiming at long-run growth and at balancing regional 
disparities must seriously consider the local structural factors that we have analyzed. In particular, far from being an arrival point, the present analysis is just a beginning in assessing the impact of local characteristics on job creation. It suggests, at the very least, that a lot could be learned from the analysis of LLS's, especially for guidance in structural and "supply side" policies. 


\section{References}

[1] Barro R.J. (1990): "Government Spending in a Simple Model of Endogenous Growth" Journal of Political Economy 98,5, part II 103-125.

[2] Becattini G. (1987): "Mercato e Forze Locali: Il Distrtto Industriale" Bologna, Il Mulino.

[3] Blanchard O. and Katz L. (1992): "Regional Evolutions" Brookings Papers on Economic Activity.

[4] Brusco S. (1982): "The Emilian Model: Productive Decentralization and Social Integration" Cambridge Journal of Economics 6, 167-184.

[5] Capparucci M. (1996): "I fattori dimensionali, tecnologici e di mercato nei differenziali retributivi delle imprese meridionali" Rassegna Economica n.4 pp. 941-980.

[6] Casavola P. and P. Sestito (2000): "Politiche di Sviluppo e Politiche del Lavoro: che sta Succedendo nel Mezzogiorno?" Manuscript, Sep. 2000, Ministero del Tesoro.

[7] P.Casavola A, Gavosto and P. Sestito (1995): "Salari e Mercato del Lavoro Locale" Lavoro e Relazioni Industriali n.4 pp. 40-95.

[8] Cuñat A. (1999): "Sectoral Allocation in the Process of Growth," Harvard Ph.D. dissertation.

[9] Decressin J. and A. Fatás (1995): "Regional Labor Market Dynamics in Europe" European Economic Review.

[10] Donzelli (1998): "La Nuova Programmazione e il Mezzogiorno."

[11] DPEF (2000): "Documento di Programmazione Economico-Finanziaria per gli anni 2000-2004" presentato dal Presidente del Consiglio dei ministri, Estate 2000.

[12] Dumais, G., G. Ellison and E.L. Glaeser (1997): "Geographic Concentration as a Dynamic Process," NBER Working Paper \# 6270.

[13] European Commission (1999): "Italy's Slow Growth in the '90's" Reports and Studies, No 5.

[14] Ferrero M. and D. Invernizzi( 1992): "La struttura retributiva dei lavoratori alle dipendenze: Evidenza empirica dagli osservatori INPS" Economia $e$ Lavoro n.1 pp. 95-116.

[15] Fujita M., P. Krugman and A.J. Venables (1999): "The Spatial Economy," MIT Press, Cambridge, London 1999.

[16] Garibaldi P. and P. Mauro (1999): "Deconstructing Job Creation" IMF manuscript. 
[17] Ginzburg A., M. Scaltriti, G. Solinas and Rossella Zoboli (1998): "Un nuovo autunno caldo nel mezzogiorno? Note in margine al dibattito sui differenziali salariali territoriali" Politica Economica, XIV.

[18] Helg R. Peri G. and Viesti G. (2000): "Abruzzo and Sicily: Catching up and Lagging behind" in European Investment Bank Papers Vol. 5 No 1.

[19] Krugman, P. and A. Venables (1995): "Globalization and the Inequality of Nations," Quarterly Journal of Economics, 110(4) 857-880.

[20] Kolko J. (1999): “Can I get some Service here?" manuscript Harvard Universisty, Nov. 1999.

[21] ISTAT (1981): "Censimento dell'Industria e dei Servizi" Istituto Nazionale di Statistica, Roma 1981.

[22] ISTAT (1991): “Censimento dell'Industria e dei Servizi” Istituto Nazionale di Statistica, Roma.

[23] ISTAT (1996): “Censimento intermedio dell'Industria e dei Servizi" Istituto Nazionale di Statistica, Roma.

[24] ISTAT (1999): "I Sistemi Locali del Lavoro" Pubblicazione dell'Istituto Nazionale di Statistica, Roma.

[25] Marimón R. and F. Zilibotti (1998): "Actual versus Virtual Employment in Europe: Is Spain Different?" European Economic Review 42 (1998) 123-153.

[26] Marshall, A. (1920): "Principles of Economics," London, Macmillan.

[27] Obstfeld M. and G. Peri (1998): "Regional Non-adjustment and Fiscal Policy" Economic Policy Apr.

[28] Paci, R. and A. Saba (1997): "The Empirics of Regional Economic Growth in Italy 1951-1993," Contributi di Ricerca Crenos, 97/1.

[29] Picci L. (1999) "Productivity and Infrastructure in the Italian Regions" Giornale degli economisti, Annali di Economia Vol. 58 N. 3-4 pp.329-353.

[30] Picci L. and F. Bonaglia (1999): "Il capitale nelle regioni italiane", WP. n. 374 DSE, University of Bologna.

[31] Scherer, F. (1984) "Using Linked Patent Data and R\&D Data to Measure Technology Flows," in Griliches (eds.) "REDD Patents and Productivity," The University of Chicago Press. 


\section{A Appendix}

\section{A.1 Production Function and Labor Demand}

We consider one industry $(z)$ in one LLS $(i)$ as the unit of our analysis. We can think of the production function, expressed in output per unit of area, as:

$$
y_{z i}=\Omega\left(e_{z i}\right)\left(G_{z}\right)^{1-\alpha-\beta} f\left(\lambda_{z} l_{z i}, \kappa_{z} k_{z i}\right),
$$

$y_{z i}$ is the output of the industry $z$ in LLS $i$. The function $f($.$) is homogeneous$ of degree $(\alpha+\beta)<1$ in $l_{z i}$ and $k_{z i}$. which are, respectively, the amounts of physical capital and labor used by sector $z$ in locality $i$, and $\kappa_{z}$ and $\lambda_{z}$ are the corresponding factor-augmenting coefficients that reflect the level of technology in sector $z$. Those terms do not have a locality subscript as we assume that technology is common to all the localities within a region. The amounts $\lambda_{z} l_{z i}$ and $\kappa_{z} k_{z i}$ should be thought as "effective factors" used in sector $z$ in LLS $i$. Function $f$ exhibits decreasing return to scale because of congestion effects. There are two factors, increasing the total productivity of the local industry: $\Omega\left(e_{z i}\right)$ is a reduced-form term capturing static agglomeration externalities for sector $z$ in locality $i ; G_{z}$ is the region-wide public capital good which measures the amount of infrastructures existing in the region.

Factor demand for industry $z$ in location $i$ is obtained by equating the factor's marginal productivity to its payment, assuming the price of goods equalized across LLS. We also assume that the return to capital is equalized across regions, and that the wage rate is set by contract and therefore exogenous for the single industry and equal across regions. We will therefore consider the condition of equality between marginal productivity of labor and wage as a "long-run" labor demand.

To simplify the analysis we consider the particular case of a Cobb-Douglas function $f=\left(\lambda_{z} l_{z i}\right)^{\alpha}\left(\kappa_{z} k_{z i}\right)^{\beta}$ and we derive the labor demand, assuming that each local industry also chooses its capital to equate its marginal productivity to its return $r$. We obtain the following expression:

$$
l_{z i}^{*}=\Phi(r, w)\left(\Omega\left(e_{z i}\right) * \lambda_{z}^{\alpha} \kappa_{z}^{\beta}\right)^{\frac{1}{1-\alpha-\beta}}\left(G_{z}\right) .
$$

where $\Phi(r, w)=\left(\frac{w^{\beta+1} \beta^{\beta} \alpha^{1-\beta}}{r^{\beta}}\right)^{\frac{1}{1-\alpha-\beta}}$. The long run labor demand at the local industry level varies across localities with the intensity of local static externalities $\Omega\left(e_{z i}\right)$. Moreover factor effectiveness, namely labor augmenting $\left(\lambda_{z}\right)$ and capital augmenting $\left(\kappa_{z}\right)$ technology and the regional stock of public capital have a positive effect on the local labor demand. In order to translate the 
predictions on the long run labor demands $\left(l_{z i}^{*}\right)$ into prediction on the growth rate of employment we assume an "ad-hoc" expression, justified by the sluggishness of employment adjustment (due to slow mobility and persistence of unemployment). We assume that the change of employment in a LLS/industry depends positively on the change of "long run" labor demand (which increases with technological growth and with growth of infrastructures) and also positively on the difference between initial employment and "steady-state" labor demand. Therefore we can summarize this relation, in qualitative terms as:

$$
\left(\Delta l_{z i}\right)_{t}=f\left(l_{z i t}, \stackrel{+}{l_{z i t}^{*}}, \Delta l_{z i}^{*}\right)
$$

From 8 , the main determinant of $\Delta l_{z i}^{*}$ are technological and infrastructure growth, and the distance between $l_{z i t}$ and $l_{z i t}^{*}$ depends on the initial conditions of employment and on the initial characteristics affecting local static externalities. The $\log$ linearized form of 8 , is equation (1) in Section 3.

\section{A.2 A Disaggregate Decomposition of the Growth Rate of GDP per Worker}

Consider an economy (a region) with many sectors $z \in Z$, in which GDP is the aggregation of sectoral value added: $p y=\Sigma_{z} p_{z} y_{z}$. Let us assume $y_{z}=$ $f_{z}\left(\kappa_{z} k_{z}, \lambda_{z} l_{z}\right)$. We allow production functions to have different capital-labor intensities across sectors. Assume competitive factor markets and constant returns to scale. Let us normalize the aggregate price level $p=\Sigma_{z}\left(y_{z} / y\right) p_{z}$ to one. Define $s_{z} \equiv \frac{p_{z} y_{z}}{\sum_{z} p_{z} y_{z}}$ as sector $z$ 's share in total value added; $\alpha_{z} \equiv \frac{r_{z} k_{z}}{p_{z} y_{z}}$ as sector $z$ 's capital share in value added; $s_{z} \equiv \frac{p_{z} y_{z}}{\sum_{z} p_{z} y_{z}}$ as sector $z$ 's share in total value added; $\gamma(x) \equiv \frac{\dot{x}}{x}$ as the growth rate of variable $x$; and $\gamma\left(a_{z}\right) \equiv$ $\alpha_{z} \gamma\left(\kappa_{z}\right)+\left(1-\alpha_{z}\right) \gamma\left(\lambda_{z}\right)$ as sector $z$ 's growth rate of TFP.

We can decompose the growth rate of GDP per worker into three terms ${ }^{24}$ :

$$
\gamma\left(\frac{y}{l}\right)=\overbrace{\sum_{z} s_{z} \gamma\left(\frac{l_{z}}{l}\right)}^{\text {factor re-allocation }}+\underbrace{\overbrace{\sum_{z} s_{z} \alpha_{z} \gamma\left(\frac{k_{z}}{l_{z}}\right)}^{\text {capital deepening }}+\overbrace{\sum_{z} s_{z} \gamma\left(a_{z}\right)}^{\text {TFP growth }}}_{\text {intensification }} .
$$

The first term on the right hand side (the "factor reallocation" term) captures the contribution to growth of an increase in the aggregate capital-labor

${ }^{24}$ This is based on Cuñat [8]. 
ratio through the reallocation of factors among sectors with different value added per worker. The second term (the "capital deepening" term) measures the contribution of the aggregate capital-labor ratio through increases in sectoral capital-labor intensities. The third term reflects total factor productivity (TFP) growth. The sum of the two last terms on the right hand side yields $\sum_{z} s_{z} \gamma\left(p_{z} y_{z} / l_{z}\right)$; we call this the "intensification term".

Assume that all sectors have the same elasticity of substitution. In this case, any region $j$ 's factor reallocation term can be written as

$$
\sum_{z} s_{z j} \gamma\left(\frac{l_{z j}}{l_{j}}\right)=\gamma\left(\frac{y_{j}}{l_{j}}\right)-\alpha_{k_{j}} \eta \gamma\left(\frac{w_{j}}{r_{j}}\right)-\sum_{z} s_{z j} \gamma\left(a_{z j}\right)
$$

where $\eta$ is the elasticity of substitution between capital and labor. Notice that if we compute region $j$ 's factor reallocation term under the assumption that it has country I's production structure, we obtain

$$
\sum_{z} s_{z I} \gamma\left(\frac{l_{z j}}{l_{j}}\right)=\sum_{z} s_{z I} \gamma\left(\frac{p_{z j} y_{z j}}{l_{j}}\right)-\alpha_{k_{I}} \eta \gamma\left(\frac{w_{j}}{r_{j}}\right)-\sum_{z} s_{z I} \gamma\left(a_{z j}\right)
$$

Let us assume that the growth rate of the wage-rental ratio $\gamma\left(\frac{w}{r}\right)$ is equal across regions within a country, and that factor-augmenting technical progress within each region is equal across sectors, i.e., $\gamma\left(\kappa_{z j}\right)=\gamma\left(\kappa_{j}\right)$ and $\gamma\left(\lambda_{z j}\right)=$ $\gamma\left(\lambda_{j}\right)$ for all $z$. Then, subtracting country $I$ 's factor reallocation term from region $j$ 's factor reallocation term computed with country $I$ 's production structure yields

$$
\begin{aligned}
& \sum_{z} s_{z I}\left[\gamma\left(\frac{l_{z j}}{l_{j}}\right)-\gamma\left(\frac{l_{z I}}{l_{I}}\right)\right]=\left[\sum_{z} s_{z I} \gamma\left(\frac{p_{z j} y_{z j}}{l_{j}}\right)-\gamma\left(\frac{y_{I}}{l_{I}}\right)\right]+ \\
& -\left[\alpha_{k_{I}}\left[\gamma\left(\kappa_{j}\right)-\gamma\left(\kappa_{I}\right)\right]+\left(1-\alpha_{k_{I}}\right)\left[\gamma\left(\lambda_{j}\right)-\gamma\left(\lambda_{I}\right)\right]\right] .
\end{aligned}
$$

Thus, with information on employment and value added by sector-region we can obtain a "pseudo-TFP" growth rate that indicates the differences in factoraugmenting technical progress between regions and the country they belong to:

$$
\begin{gathered}
\alpha_{k_{I}}\left[\gamma\left(\kappa_{j}\right)-\gamma\left(\kappa_{I}\right)\right]+\left(1-\alpha_{k_{I}}\right)\left[\gamma\left(\lambda_{j}\right)-\gamma\left(\lambda_{I}\right)\right]= \\
=\left[\sum_{z} s_{z I} \gamma\left(\frac{p_{z j} y_{z j}}{l_{j}}\right)-\gamma\left(\frac{y_{I}}{l_{I}}\right)\right]-\sum_{z} s_{z I}\left[\gamma\left(\frac{l_{z j}}{l_{j}}\right)-\gamma\left(\frac{l_{z I}}{l_{I}}\right)\right] .
\end{gathered}
$$


The data we use are from the regional database $\mathrm{CRENoS}^{25}$, updated with information from the regional accounts. This provides us with data on GDP and aggregate employment, and on real value added (in 1985 prices) and employment by sector for all Italian regions. The database disaggregates each region's economy into 17 sectors (agriculture, 10 industrial sectors, construction, 4 market-service sectors, and the non-market-service sector).

We compute $s_{z}$ as sector $z$ 's value added over value added aggregated over all sectors; growth rates $\gamma(x)$ are computed as differences between the logs of final and initial $x$. We exclude agriculture for consistency with the information on LLS's. However, the numbers obtained including agriculture are highly correlated with the numbers we report in Section 4.

${ }^{25}$ See Paci and Saba [28]. 